\title{
Quality of Care Associated with Common Chronic Diseases in a 9-State Medicaid Population Utilizing Claims Data: An Evaluation of Medication and Health Care Use and Costs
}

\author{
Julie L. Priest, MSPH, C. Ron Cantrell, PhD, Jack Fincham, PhD, RPh, \\ Christopher L. Cook, PharmD, PhD, and Steven P. Burch, PhD ${ }^{1}$
}

\begin{abstract}
The objective of this cross-sectional, retrospective study was to utilize claims data to establish a quality-of-care benchmark in a large multistate Medicaid population overall and by race. Quality of care and medication adherence (persistence and compliance) per national treatment guidelines, and health care costs/utilization were assessed across common chronic conditions in a large, 9-state Medicaid population. Overall, quality of care was suboptimal across conditions. Over $15 \%$ of asthma patients had $\geq 1$ asthma-related emergency room/hospital event and $12 \%$ of chronic obstructive pulmonary disease patients had a Level II or III exacerbation. Only $36 \%$ of depression patients filled any antidepressant medication within 90 days of new episode. Only $45 \%$ of diabetes patients received $\geq 2$ A1c tests. Patients who filled a prescription for any acceptable pharmacotherapy ranged from $35 \%$ (depression) to $83 \%$ (heart failure [HF]). Persistence for those filling any acceptable medication ranged from $16 \%$ (asthma) to $68 \%$ (HF). Compliance for patients filling $\geq 2$ prescriptions ranged from $27 \%$ (asthma) to $75 \%(\mathrm{HF})$. Blacks had the lowest medication compliance and persistence for all conditions except hyperlipidemia. The results highlight the need to assess and improve quality across the spectrum of care, both overall and by race. (Population Health Management 2011;14:43-54)
\end{abstract}

\section{Introduction}

$\mathbf{P}$ Ublicly finANCED health insurance COVERAge THROUGH Medicaid is designed to improve the health, quality of life, and longevity of underserved and vulnerable populations by providing health care to the disabled, elderly, and the nonelderly poor. Although not targeted to the publicly insured, results from the RAND Community Quality Index (CQI) study demonstrated that adults living in the United States receive only about half of the recommended processes involved in basic care for acute and chronic conditions. ${ }^{1}$ Recent research suggests that these goals are not being met for many publicly insured Americans. ${ }^{2-6}$ Medicaid coverage, compared with other insurance types such as commercial or self-pay insurance, has shown an association with poorer access to preventive, acute, and follow-up care. ${ }^{2,3}$ The reasons for these discrepancies in care and outcomes based on insurance type are likely multifactorial and could include insufficient funding, sicker patients, and subpar health care providers and organizations.
The Medicaid population is among the main targets of federally funded initiatives to improve the quality of health care. ${ }^{4}$ For all the interest in improving quality of care in the Medicaid population, surprisingly little is known about the current baseline quality of care for common diseases for Medicaid-dependent individuals on a population health level. Studies of quality of care have generally been limited to single conditions or specific subsets of the Medicaid population. For example, a study comparing insurance status and diabetes quality of care at community health centers revealed that Medicaid patients received low quality of care, similar to the uninsured. ${ }^{4}$ In another study evaluating quality of care, Medicaid managed care was compared to commercial managed care and it was found that Medicaid patients received lower quality of care than the commercially insured. ${ }^{5}$

Similarly, while previous studies have been conducted to evaluate differences in medication treatment and adherence by race, the majority have focused on specific conditions or subsets with varying end points and methodologies. Studies

\footnotetext{
${ }^{1}$ GlaxoSmithKline, Research Triangle Park, North Carolina.

${ }^{2}$ School of Pharmacy, University of Missouri, Kansas City, Missouri.
} 
have consistently indicated that disparities of care, including medication treatment and adherence, exist between whites and minorities within Medicaid populations. ${ }^{6-8}$

Earlier studies assessing quality of care have highlighted clear issues across insured populations. The RAND study findings, in particular, were profound and suggested that change was needed. These analyses, however, are difficult to recreate within practices because of the cost and time associated with survey methodology and chart reviews. The current study seeks to build upon these findings and utilize claims data, which are readily available and frequently used to profile individual populations, to establish a quality of care benchmark in a large multistate Medicaid population, both overall and by race. The study is not meant to draw conclusions or test hypotheses but rather to profile and describe the population using common managed care definitions and techniques that can potentially provide a more widespread index to aid managed care utilization and quality efforts. This type of index, developed on a large population using standard methods, can aid decision makers within Medicaid to identify the best opportunities for improvement to optimize health care quality and spend. In a time of limited resources and budgets, rising costs, and the need for improved outcomes, this type of approach can help enable cost-effective activities and spends as it adds to current utilization activities. This is especially crucial now that one resultant effect of the recently passed health care reform legislation is to lower the financial eligibility criteria for Medicaid coverage.

\section{Methods}

A cross-sectional, retrospective study, using a 9-state Medicaid database, was conducted to assess quality of care and medication use and adherence (persistence and compliance) based on nationally recognized treatment guidelines, and health care costs and utilization across a spectrum of chronic conditions. The conditions evaluated were chosen because of their high prevalence, financial impact, chronic nature, and the availability of clearly defined guidelines of care. They include asthma, chronic obstructive pulmonary disease (COPD), coronary artery disease (CAD), new episodes of depression, diabetes, heart failure (HF), hyperlipidemia (HL), and hypertension (HTN).

\section{Data source}

Data were obtained from the Thomson Reuters MarketScan Multi-State Medicaid Database, ${ }^{16}$ a claims data source with patient enrollment information linked to pharmacy and physician/medical claims information from 9 states. Due to contractual obligations, the identity of the state Medicaid programs represented is unknown. The MarketScan MultiState Medicaid Database is fully de-identified and Health Insurance Portability and Accountability Act compliant.

\section{Sample}

In order to establish an annual benchmark assessment of utilization, all analyses were conducted using 2007 data. Patients were either identified in 2006 or in the first 6 months of 2007 and were required to be eligible for services on the last day of 2007 to ensure that they were active, relevant patients. The study design allowed patients to enter the study population during 2007 but required at least 6 months of follow-up to be included. Here, the intent was to include patients entering the patient mix during 2007 who would have been of interest for current year assessment and current year care management activities. Specifically, patients with at least 1 of the target conditions were identified (based on disease-specific criteria described in Table 1) using data from January 1, 2006 to June 30, 2007 for all conditions except depression. New episode depression patients who did not have a depression medication fill or diagnosis in the 6 months prior to the index date were selected, based on disease-specific criteria, between January 1, 2007 and June 30, 2007. In order to select active patients who were currently enrolled and had sufficient data to help ensure relevance, patients were required to have at least 6 months of data available after identification and were required to be eligible for services on the last date of the measurement year (December 31, 2007). The first identification of any condition (ID index) was based on the first occurrence of the inclusion criteria.

\section{Measures and data analysis}

As discussed, all analyses utilized data from 2007. Recipients with dual Medicaid/Medicare eligibility or people $\geq 65$ years of age were excluded from analyses because of the potential for missing claims. All data were summarized with descriptive statistics; no hypothesis testing was undertaken. Data were summarized separately for each condition overall and stratified by race.

Quality measures. Measures of quality of care were determined for asthma, COPD, depression, and diabetes in 2007. These conditions were chosen based on the availability of current national guidelines assessing overall quality indicators of care received or other claims-based markers available that could provide an indication of quality such as asthma rescue medication use. The quality of care measure for asthma included the percentage of patients with at least 4 short-acting beta-agonist (SABA) prescription fills. ${ }^{17,18}$ This measure was chosen because the frequent use of rescue medications has been shown to increase the risk of exacerbation. ${ }^{17,18}$ This measure is not definitive but rather intended to identify what percent of patients are potentially uncontrolled. Quality of care measures for COPD included the percentages of patients with a Level II (COPD-related hospitalization) or Level III exacerbation (respiratory failure) according to the American Thoracic Society guidelines. ${ }^{19}$ The quality of care measure for depression, based on Kaiser Permanante clinical practice guidelines, ${ }^{20}$ was the percentage of newly diagnosed patients with depression who filled at least 1 antidepressant prescription within 90 days from the index diagnosis. Measures utilized to assess diabetes quality of care were based on the American Diabetes Association guidelines and included the percentages of patients with at least $1 \mathrm{~A} 1 \mathrm{c}$ test, at least 1 low-density lipoprotein (LDL) test, and an eye exam, as well as the percentage of patients who received the minimum acceptable number of A1c tests (ie, $\geq 2$ ) in a year for the subset of patients with a minimum of 12 months continuous coverage. ${ }^{21}$ For CAD, HF, and HTN, a proxy measure for quality was persistence and compliance with prescribed therapies. 
Table 1. Disease-Specific Criteria for Inclusion in the Study

\begin{tabular}{|c|c|c|c|}
\hline Disease & Inclusion Criteria & Exclusion Criteria & Any Acceptable Medications \\
\hline Asthma & $\begin{array}{l}\text { Patents were included if they } \\
\text { were } \geq 4 \text { years of age and had } 1 \\
\text { medical encounter with } \\
\text { asthma (ICD- } 9 \text { code } 493 . x x \text { ) as } \\
\text { the primary diagnosis, OR at } \\
\text { least } 2 \text { outpatient encounters } \\
\text { with asthma as a secondary } \\
\text { diagnosis, OR a diagnosis and } \\
\text { an asthma medication fill. }\end{array}$ & $\begin{array}{l}\text { Patents were excluded if they } \\
\text { had any diagnosis of } \\
\text { emphysema or COPD. }\end{array}$ & $\begin{array}{l}\text { Any appropriate asthma } \\
\text { medication included } \\
\text { cromolyn, inhaled } \\
\text { corticosteroids (ICS), } \\
\text { ICS + long-acting beta } \\
\text { agonists (LABA) fixed-dose } \\
\text { combination, leukotriene } \\
\text { modifiers (LTM), and } \\
\text { xanthines }\end{array}$ \\
\hline $\begin{array}{l}\text { Chronic obstructive } \\
\text { pulmonary disease } \\
\text { (COPD) }\end{array}$ & $\begin{array}{l}\text { Patients were included if they } \\
\text { were } \geq 40 \text { years of age and had } \\
1 \text { medical encounter with a } \\
\text { primary diagnosis of COPD } \\
\text { (ICD-9 code } 491 . x x, 492 . x x \text {, or } \\
496 . x x \text { ) or } 2 \text { with secondary } \\
\text { diagnoses of COPD. }\end{array}$ & None & $\begin{array}{l}\text { Any appropriate COPD } \\
\text { medication included } \\
\text { anticholinergics (AC), LTM, } \\
\text { xanthines, and ICS + LABA, } \\
\text { short-acting beta-agonist } \\
\text { (SABA) + AC fixed-dose } \\
\text { combinations. }\end{array}$ \\
\hline $\begin{array}{l}\text { Coronary artery } \\
\text { disease (CAD) }\end{array}$ & $\begin{array}{l}\text { Patients were included if they } \\
\text { had a diagnosis of CAD (ICD-9 } \\
\text { codes } 410 . x \text { to } 414 . x \text { or } 429.2 x)\end{array}$ & None & $\begin{array}{l}\text { Any appropriate CAD } \\
\text { medication included } \\
\text { angiotensin-converting } \\
\text { enzyme (ACE) inhibitors, } \\
\text { angiotensin receptor } \\
\text { blocker (ARB), beta- } \\
\text { blockers, anticoagulants, } \\
\text { antiplatelets, and any fixed- } \\
\text { dose combination product } \\
\text { of any of these. }\end{array}$ \\
\hline Depression & $\begin{array}{l}\text { Patients were included if they } \\
\text { had } 1 \text { medical encounter with } \\
\text { major depression (ICD-9 codes } \\
\text { 296.2, 296.3, 298.0,300.4, 309.1, } \\
\text { or 311) as the primary } \\
\text { diagnosis, OR } 2 \text { outpatient or } 1 \\
\text { inpatient encounter with } \\
\text { secondary diagnoses of } \\
\text { depression }\end{array}$ & $\begin{array}{l}\text { Patients with schizophrenia or } \\
\text { bipolar disorder were } \\
\text { excluded. }\end{array}$ & $\begin{array}{l}\text { Any appropriate depression } \\
\text { medication included } \\
\text { monoamine oxidase } \\
\text { inhibitors, selective } \\
\text { norepinephrine reuptake } \\
\text { inhibitors, selective } \\
\text { serotonin reuptake } \\
\text { inhibitors, tricyclic } \\
\text { antidepressants, and other } \\
\text { antidepressants }\end{array}$ \\
\hline Diabetes & $\begin{array}{l}\text { Patients were included if they } \\
\text { had } 2 \text { medical encounters for } \\
\text { diabetes (ICD-9 code } 250 . x x \text { ), } \\
\text { or } 1 \text { medical encounter for } \\
\text { diabetes and a prescription fill } \\
\text { for insulin, or an oral } \\
\text { antidiabetic medication, or } 1 \\
\text { prescription fill for insulin. }\end{array}$ & $\begin{array}{l}\text { Patients were excluded if they } \\
\text { had only } 1 \text { inpatient or } \\
\text { outpatient encounter for } \\
\text { type I diabetes and lacked a } \\
\text { prescription fill for insulin } \\
\text { or an oral antidiabetic } \\
\text { medication. }\end{array}$ & $\begin{array}{l}\text { Any appropriate diabetes } \\
\text { medication included alpha- } \\
\text { glucosidase inhibitors, } \\
\text { biguanides, D- } \\
\text { phenylalanine derivative, } \\
\text { meglitinides, sulfonylureas, } \\
\text { thiazolidinedione or any } \\
\text { fixed dose combination of } \\
\text { these. Insulin was included } \\
\text { in any appropriate } \\
\text { medication percentages and } \\
\text { excluded in any appropriate } \\
\text { oral medication percentage } \\
\text { and adherence measures. }\end{array}$ \\
\hline Heart failure & $\begin{array}{l}\text { Patients were included if they } \\
\text { had a diagnosis of heart failure } \\
\text { (ICD-9 codes 398.91, 428.xx, } \\
\text { 402.01, 402.11, 402.91, 404.01, } \\
\text { 404.11, 404.91, 404.03, 404.13, } \\
404.93 \text { ) }\end{array}$ & None & $\begin{array}{l}\text { Any appropriate cardiovascular } \\
\text { medication included ACE } \\
\text { inhibitors, alpha-beta } \\
\text { blockers, ARB, beta- } \\
\text { blockers, calcium channel } \\
\text { blockers, digitalis, direct } \\
\text { vasodilators, diuretics, } \\
\text { nitrates, antiarrythmias, } \\
\text { anticoagulants, } \\
\text { antiplatelets, any } \\
\text { appropriate lipid-lowering } \\
\text { medication, or any fixed- } \\
\text { dose combination product } \\
\text { of any of these. }\end{array}$ \\
\hline
\end{tabular}


TABle 1. (CONTINUEd)

\begin{tabular}{|c|c|c|c|}
\hline Disease & Inclusion Criteria & Exclusion Criteria & Any Acceptable Medications \\
\hline Hyperlipidemia & $\begin{array}{l}\text { Patients were included if they } \\
\text { had a diagnosis of } \\
\text { hyperlipidemia (ICD-9 codes } \\
272.0-272.4 \text { or } 272.9 \text { ) or had a } \\
\text { prescription fill for at least } 1 \\
\text { antihyperlipidemic agent. }\end{array}$ & $\begin{array}{l}\text { Patients were excluded if they } \\
\text { had evidence of CAD (ICD- } \\
9 \text { codes } 410 . x \text { to } 414 . x \text {, or } \\
429.2 x \text { ). }\end{array}$ & $\begin{array}{l}\text { Any appropriate lipid-lowering } \\
\text { medication included statins, } \\
\text { bile acid sequestrants, or } \\
\text { other antihyperlipidemic } \\
\text { medications (clofibrate, } \\
\text { gemfibrozil, nicotinic acid, } \\
\text { ezetimibe, and fenofibrate). }\end{array}$ \\
\hline Hypertension & $\begin{array}{l}\text { Patients were included if they } \\
\text { were diagnosed with } \\
\text { hypertension (ICD-9 codes } \\
\text { 401.xx to } 405 . x x \text { ). }\end{array}$ & $\begin{array}{l}\text { Patients were excluded if they } \\
\text { had evidence of heart } \\
\text { failure (ICD-9 codes 398.91, } \\
\text { 428.xx, 402.01, } 402.11, \\
402.91,404.01,404.11, \\
\text { 404.91, 404.03, } 404.13, \\
404.93) \text {, stroke }(434.91, \\
\text { 434.11, 430, } 431,432.0- \\
432.9,434.01) \text {, or } \\
\text { myocardial infarction } \\
\text { (410.x1). }\end{array}$ & $\begin{array}{l}\text { Any appropriate hypertensive } \\
\text { medication included ACE } \\
\text { inhibitors, alpha-adrenergic } \\
\text { agonists, alpha-beta } \\
\text { blockers, ARB, beta- } \\
\text { blockers, calcium channel } \\
\text { blockers, central alpha } \\
\text { agonists, direct } \\
\text { vasodilators, diuretics, } \\
\text { peripheral agents, and any } \\
\text { fixed-dose combination } \\
\text { product of any of these. }\end{array}$ \\
\hline
\end{tabular}

Condition-specific inclusion criteria including diagnosis codes and medications were obtained from published literature and current treatment guidelines $\mathrm{s}^{17,19,20,22-26}$ for each condition of interest.

Medication use, persistence, and compliance. The percentage of patients who filled a prescription for any acceptable therapy during the most recent 6 to 12 months was calculated for each chronic disease with the exception of new episode depression patients, for which 6 months was utilized. "Any acceptable therapy" was defined for each disease according to disease-specific national treatment guidelines ${ }^{17,19,20,22-26}$ (Table 1). This measure is not expected to be $100 \%$ for diabetes because some type 2 patients' diabetes can be controlled with diet and exercise, particularly new patients. Instead, for diabetes, this assessment provides an index that is more in line with national Medicaid rates and, while not a $100 \%$ established rate, can yield valuable information about current medication use.

Medication persistence was calculated for patients who filled at least 1 acceptable medication and utilized the proportion of days covered (PDC), defined as the total days' supply from the first fill to the end of the year divided by the number of days between the first fill and the last day of the year for all conditions except depression. Depression medication persistence was measured in the 6-month period from index date. By definition, patients must have had at least 1 fill for the medication of interest in the last year of data and at least 6 months of eligibility from the first prescription fill in the last year of data to the last day of available data in order to be included in the persistence analyses. The percentage of patients with persistence $\geq 80 \%$ was determined and reported as the percent of persistent patients for each chronic disease.

Medication compliance was calculated for patients who filled at least 2 acceptable medications to assess time to fill and utilized the medication possession ratio (MPR), defined as the total days' supply between the first and last fills (not including the last fill's supply) divided by the total number of days between the first and last fills for any acceptable therapy in the most recent 6 to 12 months for all conditions except depression. Depression compliance was measured over the 6-month period from the first fill. By definition, to be included in the compliance calculation patients must have had at least 2 fills in the last year of data (or within 6 months for depression) for the medication of interest and at least 6 months of continuous eligibility from the first prescription fill in the last year of data to the last day of available data. The percentage of patients with a MPR $\geq 80 \%$ was determined and reported as the percent of compliant patients for each chronic disease.

Patient use of insulin was excluded from the diabetes cohort when assessing persistence and compliance because the data for this injectable medication were not considered to be as reliable as those for oral medications.

Health care costs and utilization. Health care cost measures included medical costs (inpatient, emergency room [ER], and outpatient medical claims), pharmacy costs, and total costs (medical + pharmacy). Measures of health care utilization included the percentage of patients with at least 1 ER visit, the percentage of patients with at least 1 hospitalization, as well as the mean number of visits by type. Both allcause and disease-related health care costs and utilization were determined. Medical claims with a primary diagnosis of the condition of interest and pharmacy claims with National Drug Codes mapped to the disease classes described in Table 1 were considered to be disease related. Because follow-up periods varied from 6 to 12 months among patients, data on health care resource costs and use of care were annualized. Only patients enrolled in Medicaid fee-for-service (FFS) health plans were included in the analyses of health care costs to obtain the detailed cost information for services provided that were not available in the database for patients enrolled in a managed Medicaid plan.

\section{Results}

During the identification period there were 2,812,849 enrolled beneficiaries eligible for selection who also met the 
Table 2. Disease Prevalence and Patient Demographics $(N=2,812,849)$

\begin{tabular}{lcccccccc}
\hline & Asthma & COPD & CAD & Depression & Diabetes & Heart Failure & HL & HTN \\
\hline Prevalence, n (\%) & $123,066(4)$ & $27,066(1)$ & $30,466(1)$ & $8,945(0.3)$ & $86,499(3)$ & $18,018(1)$ & $111,358(4)$ & $128,731(5)$ \\
Mean age, y (SD) & $15.4(13.2)$ & $53.1(6.6)$ & $50.6(10.9)$ & $25.6(15.5)$ & $44.8(14.6)$ & $46.9(15.7)$ & $41.4(17.6)$ & $45.1(13.6)$ \\
Male, n (\%) & $60,576(49)$ & $9,927(37)$ & $13,026(43)$ & $2,995(33)$ & $27,552(32)$ & $7,134(40)$ & $39,000(35)$ & $41,733(32)$ \\
Race, n (\%) & & & & & & & & \\
$\quad$ Black & $48,489(39)$ & $5,969(22)$ & $8,348(27)$ & $2,295(26)$ & $31,897(37)$ & $7,500(42)$ & $32,941(30)$ & $53,927(42)$ \\
$\quad$ Hispanic & $3,397(3)$ & $209(1)$ & $303(1)$ & $147(2)$ & $1,397(2)$ & $214(1)$ & $1,791(2)$ & $1,322(1)$ \\
$\quad$ White & $50,103(41)$ & $18,004(67)$ & $15,265(50)$ & $5,042(56)$ & $36,542(42)$ & $7,854(44)$ & $48,432(43)$ & $50,418(39)$ \\
$\quad$ Other & $21,077(17)$ & $2,884(11)$ & $6,550(21)$ & $1,461(16)$ & $16,663(19)$ & $2,450(14)$ & $28,194(25)$ & $23,064(18)$ \\
Plan Type, n (\%) & & & & & & & & \\
$\quad$ FFS & $28,419(23)$ & $13,305(49)$ & $11,724(38)$ & $2,828(32)$ & $31,813(37)$ & $7,104(39)$ & $36,028(32)$ & $44,477(35)$ \\
$\quad$ Managed & $94,647(77)$ & $13,761(51)$ & $18,742(62)$ & $6,117(68)$ & $54,686(63)$ & $10,914(61)$ & $75,330(68)$ & $84,254(65)$ \\
\hline
\end{tabular}

CAD, coronary artery disease; COPD, chronic obstructive pulmonary disease; FFS, fee for service; HL, hyperlipidemia; HTN, hypertension.

inclusion and exclusion criteria. The average age of the study population was 15.7 years, 56\% were female, and 30\% were enrolled in a FFS plan. Whites made up the majority of the population $(44 \%)$, followed by black (37\%), Hispanic $(4 \%)$, and other $(15 \%)$. Patients were selected for each study population from this pool of enrollees. Prevalence and demographics for each disease are presented in Table 2. Of the 8 conditions studied, the most prevalent were HTN (5\%), asthma (4\%), HL (4\%), and diabetes $(3 \%)$. The average age ranged from 15.4 years for asthma patients to 53.1 years for COPD patients. Similar to the total population, females were the slight majority (51\%) for asthma and CAD (57\%), but there were disproportionately higher numbers of females in all other conditions with the highest rates found in diabetes and HTN (68\%). For most conditions, the distribution of patients by race was similar to the total population with the majority of patients being white (39\% to $50 \%)$, followed by black ( $27 \%$ to $42 \%)$, other (14\% to $25 \%)$, and Hispanic ( $1 \%$ to $3 \%)$; exceptions were COPD and depression, which were disproportionately white $(67 \%$ and $56 \%$, respectively) (Table 2$)$.

\section{Quality measures}

Quality measure results are presented in Figure 1 for asthma, COPD, depression, and diabetes. Overall among asthma patients, $23 \%$ filled 4 or more SABA prescriptions in 2007. Other race patients tended to have the highest percentage of patients filling SABA (32\%) above this threshold. For COPD, $12 \%$ of all patients had a Level II or Level III exacerbation. Only 31\% of new depression patients filled any medication for their condition within 90 days of their diagnosis. Blacks and other patients had the lowest depression

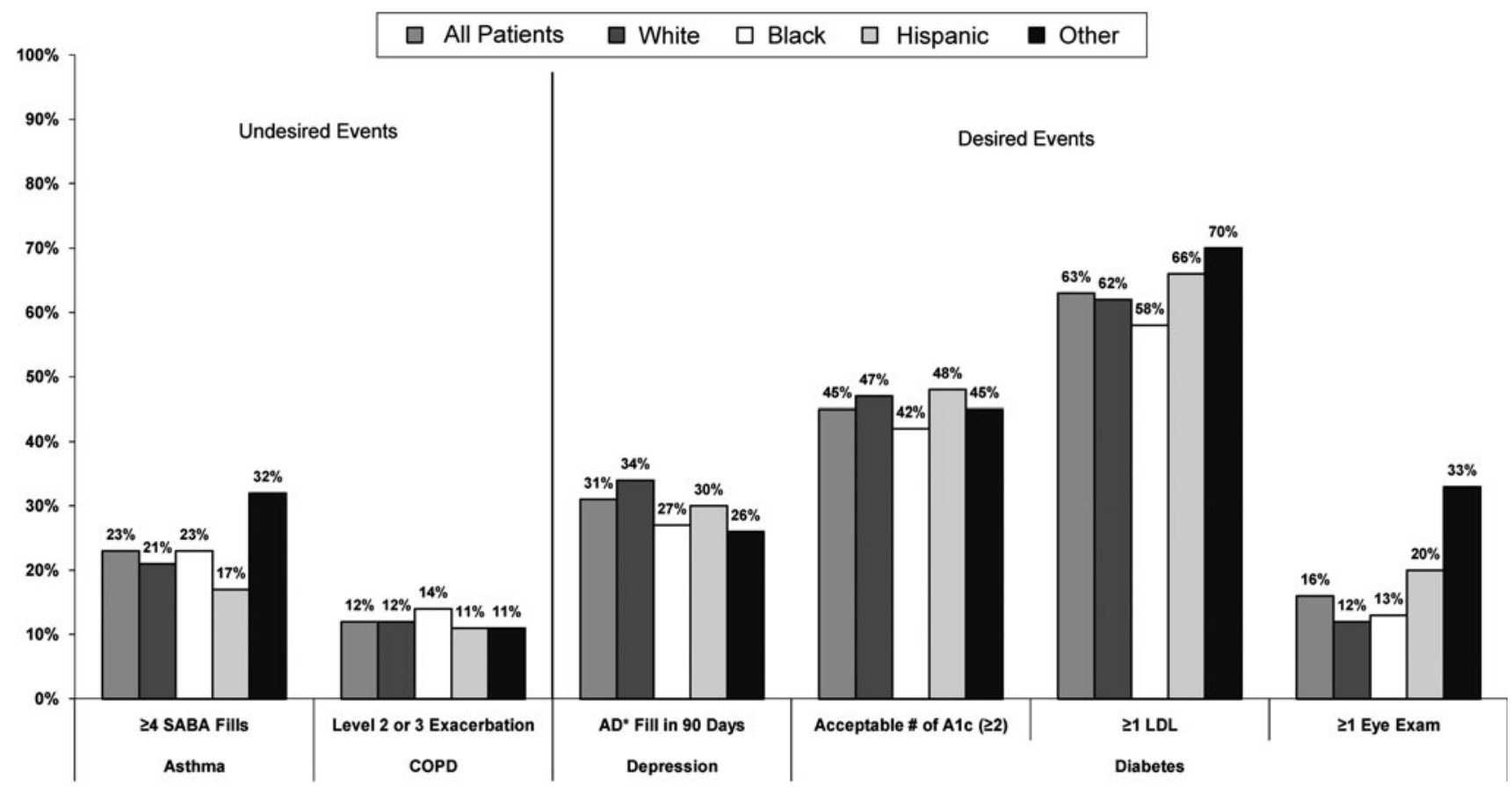

FIG. 1. Results on quality measures for asthma, COPD, depression, and diabetes, overall, and by race. ${ }^{*} \mathrm{AD}$ is defined as any antidepressant medication fill. COPD, chronic obstructive pulmonary disease; LDL, low-density lipoprotein; SABA, shortacting beta-agonist. 


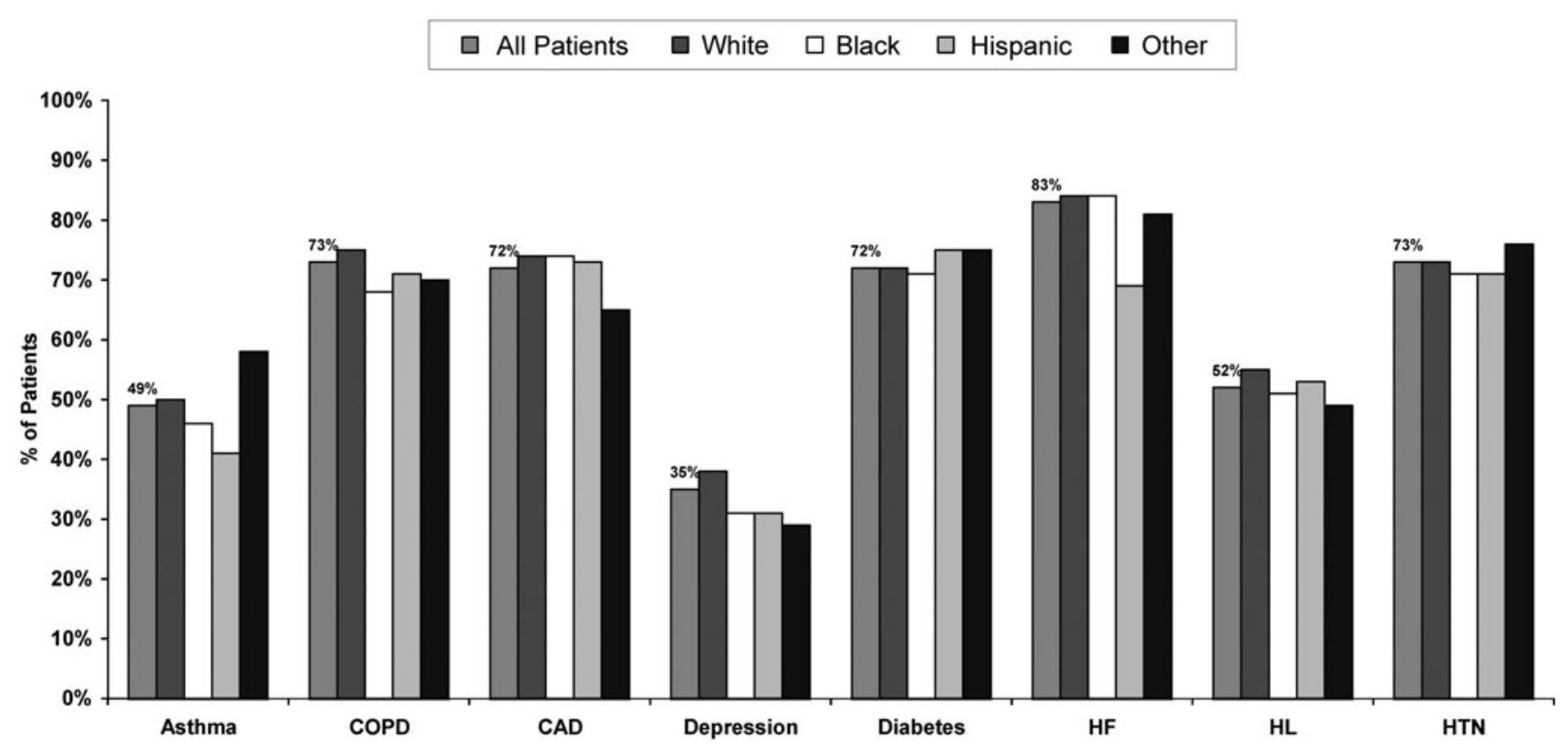

FIG. 2. Percent of patients filling any acceptable therapy by condition overall and by race. CAD, coronary artery disease; COPD, chronic obstructive pulmonary disease; HF, heart failure; HL, hyperlipidemia; HTN, hypertension.

quality measure rates, with only $27 \%$ and $26 \%$ filling any medication compared with $34 \%$ of whites. Among patients with diabetes, $70 \%$ received at least $1 \mathrm{~A} 1 \mathrm{c}$ test in a year, and only $45 \%$ had the minimum acceptable number of 2 tests in the year. Likewise, only $63 \%$ of patients with diabetes had an LDL test and only $16 \%$ received an eye exam.

\section{Medication use, persistence, and compliance}

Overall, the percentage of patients who filled any acceptable medication for their condition in 2007 was suboptimal
(Fig. 2). The largest racial differences for patients filling any acceptable therapy were seen among patients with HF, asthma, and depression.

The percentage of persistent patients ( $\geq 80 \%$ PDC) by condition are displayed in Figure 3. The largest differences among the races were found between HTN, CAD, and HL patients.

The percentage of compliant patients ( $\geq 80 \%$ MPR) from low to high was similar to persistence in terms of the order of the conditions (Fig. 4). Similar racial differences were seen for compliance with the largest differences among HL, CAD, and HTN patients.

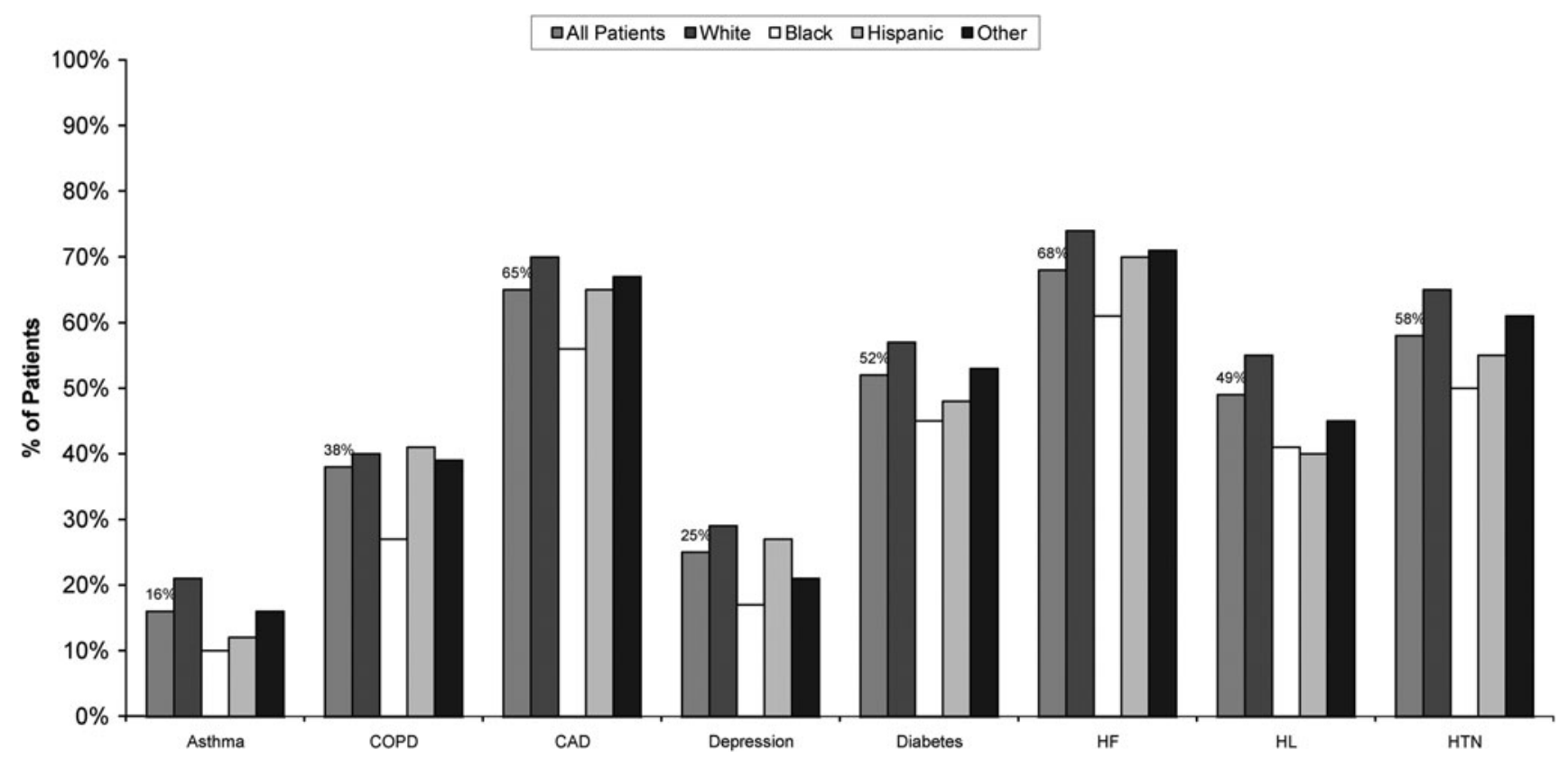

FIG. 3. Persistence for any acceptable therapy by condition overall and by race. CAD, coronary artery disease; COPD, chronic obstructive pulmonary disease; HF, heart failure; HL, hyperlipidemia; HTN, hypertension. 


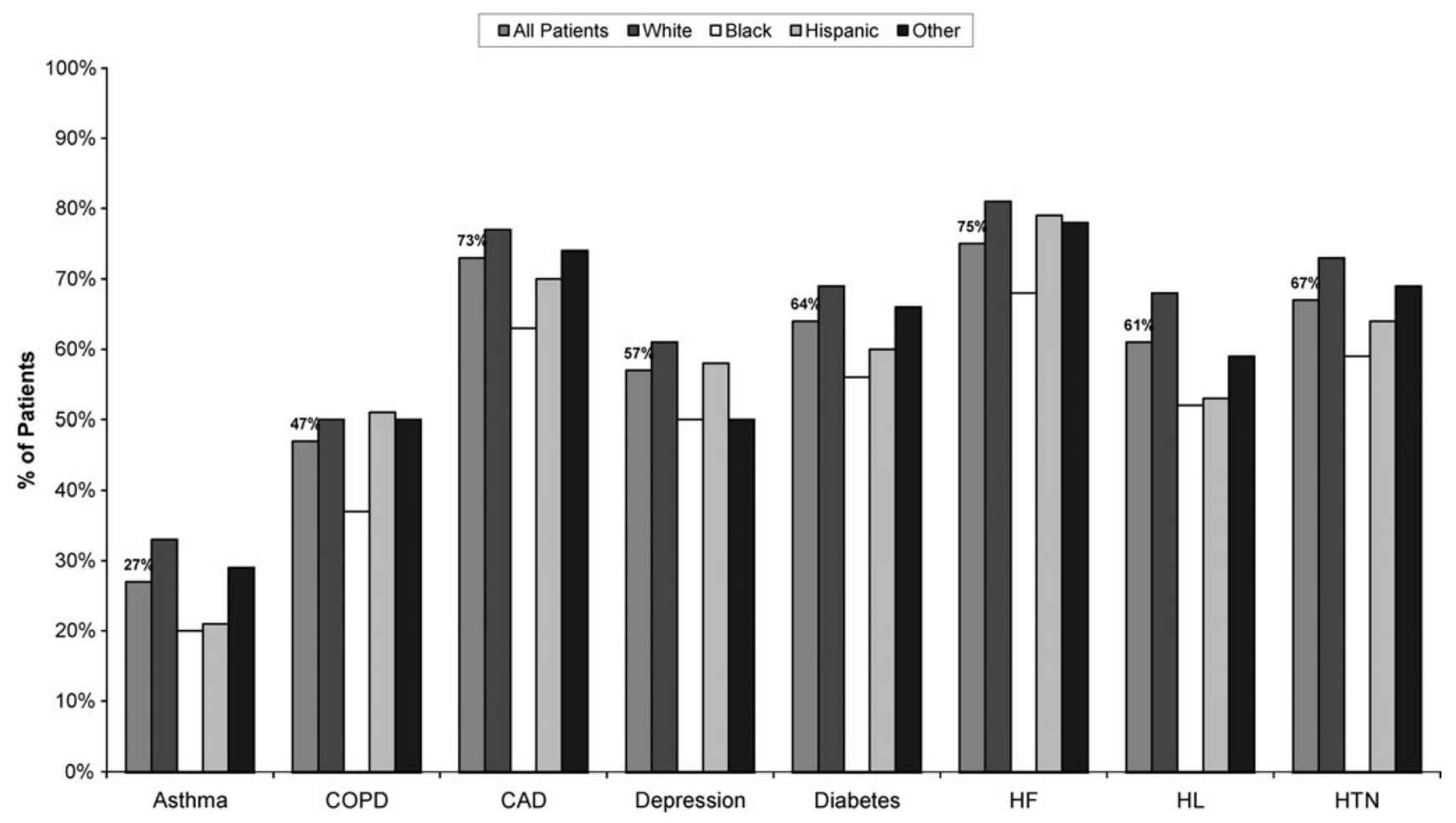

FIG. 4. Compliance results for any acceptable therapy by condition overall and by race. CAD, coronary artery disease; COPD, chronic obstructive pulmonary disease; HF, heart failure; HL, hyperlipidemia; HTN, hypertension.

Health care costs and utilization

The 4 most costly conditions for all-cause per-person peryear costs were HF, CAD, COPD, and diabetes (Fig. 5). The majority of the costs were medical expenses, which re- presented two thirds to three quarters of the total expenses across all conditions. The same conditions represented the top 4 most costly conditions for disease-related expenditures (Table 3). Two conditions showed the greatest difference between races. On average, black and other race patients cost

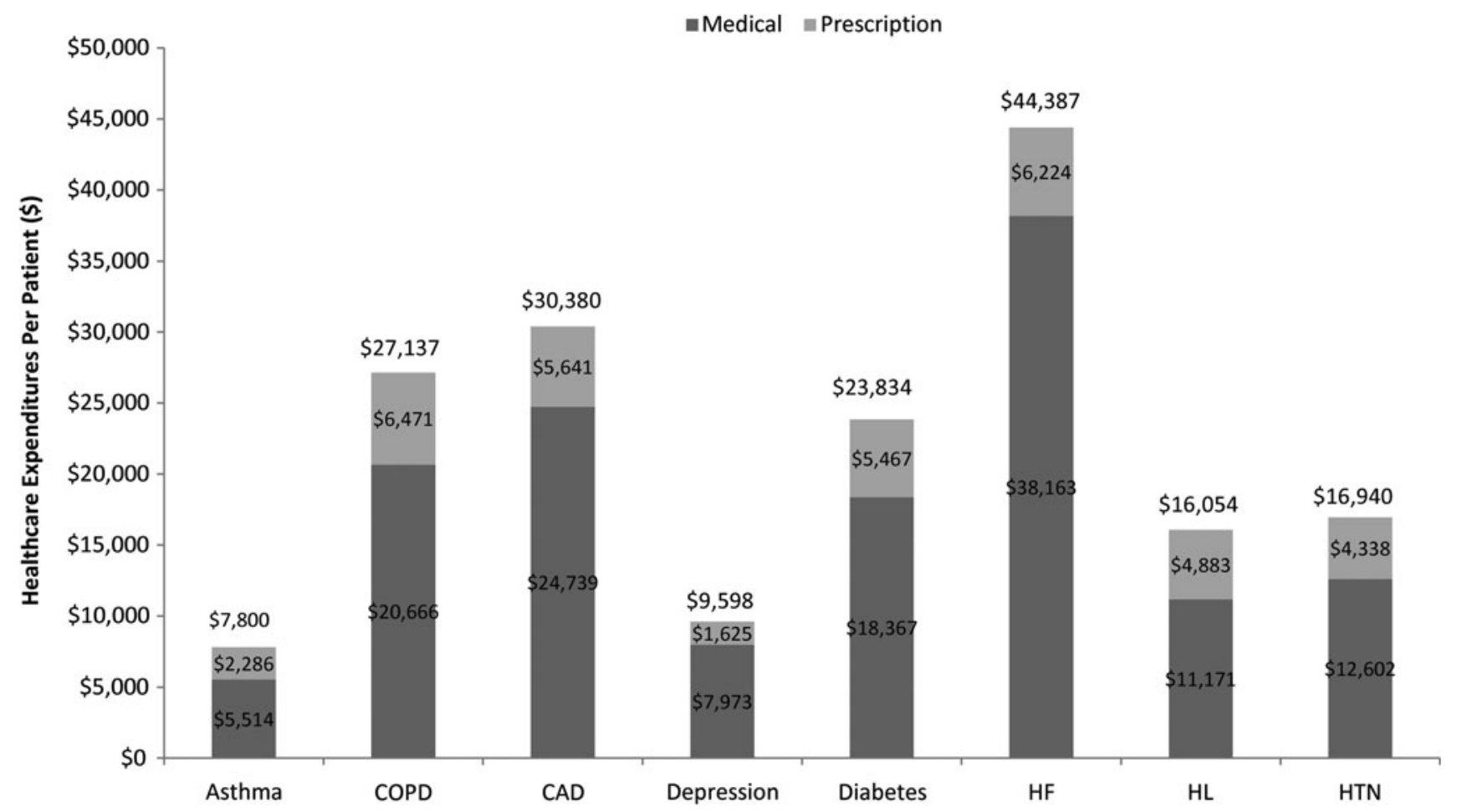

FIG. 5. All-cause per-person per-year costs by condition. CAD, coronary artery disease; COPD, chronic obstructive pulmonary disease; HF, heart failure; HL, hyperlipidemia; HTN, hypertension. 
Table 3. Disease-Related Per-Patient Per-Year Health Care Expenditures by Condition and Race

\begin{tabular}{|c|c|c|c|c|c|}
\hline Disease-Related Expenditures & All Patients & White & Black & Hispanic & Other \\
\hline \multicolumn{6}{|l|}{ Asthma } \\
\hline Total costs (Medical + Pharmacy) & $\$ 1,013$ & $\$ 835$ & $\$ 1,412$ & $\$ 843$ & $\$ 1,756$ \\
\hline Pharmacy & $\$ 659$ & $\$ 631$ & $\$ 698$ & $\$ 536$ & $\$ 957$ \\
\hline Medical & $\$ 354$ & $\$ 204$ & $\$ 714$ & $\$ 307$ & $\$ 799$ \\
\hline \multicolumn{6}{|c|}{ Chronic obstructive pulmonary disease (COPD) } \\
\hline Total costs (Medical + Pharmacy) & $\$ 3,391$ & $\$ 3,368$ & $\$ 3,372$ & $\$ 2,835$ & $\$ 4,008$ \\
\hline Pharmacy & $\$ 1,212$ & $\$ 1,261$ & $\$ 944$ & $\$ 1,007$ & $\$ 1,231$ \\
\hline Medical & $\$ 2,179$ & $\$ 2,107$ & $\$ 2,428$ & $\$ 1,829$ & $\$ 2,777$ \\
\hline \multicolumn{6}{|l|}{ Coronary artery disease } \\
\hline Total costs (Medical + Pharmacy) & $\$ 4,987$ & $\$ 4,747$ & $\$ 5,997$ & $\$ 3,093$ & $\$ 4,902$ \\
\hline Pharmacy & $\$ 1,210$ & $\$ 1,248$ & $\$ 1,059$ & $\$ 1,135$ & $\$ 1,286$ \\
\hline Medical & $\$ 3,777$ & $\$ 3,499$ & $\$ 4,938$ & $\$ 1,957$ & $\$ 3,616$ \\
\hline \multicolumn{6}{|l|}{ Depression } \\
\hline Total costs (Medical + Pharmacy) & $\$ 1,320$ & $\$ 1,305$ & $\$ 1,850$ & $\$ 2,756$ & $\$ 1,243$ \\
\hline Pharmacy & $\$ 103$ & $\$ 108$ & $\$ 61$ & $\$ 90$ & $\$ 121$ \\
\hline Medical & $\$ 1,217$ & $\$ 1,137$ & $\$ 1,607$ & $\$ 2,544$ & $\$ 1,053$ \\
\hline \multicolumn{6}{|l|}{ Diabetes } \\
\hline Total costs (Medical + Pharmacy) & $\$ 2,751$ & $\$ 2,486$ & $\$ 3,282$ & $\$ 2,071$ & $\$ 3,099$ \\
\hline Pharmacy & $\$ 1,018$ & $\$ 1,052$ & $\$ 946$ & $\$ 916$ & $\$ 1,064$ \\
\hline Medical & $\$ 1,733$ & $\$ 1,434$ & $\$ 2,335$ & $\$ 1,155$ & $\$ 2,035$ \\
\hline \multicolumn{6}{|l|}{ Heart failure (HF) } \\
\hline Total costs (Medical + Pharmacy) & $\$ 6,009$ & $\$ 4,265$ & $\$ 9,020$ & $\$ 2,560$ & $\$ 9,304$ \\
\hline Pharmacy & $\$ 1,055$ & $\$ 1,096$ & $\$ 984$ & $\$ 619$ & $\$ 1,127$ \\
\hline Medical & $\$ 4,954$ & $\$ 3,170$ & $\$ 8,036$ & $\$ 1,941$ & $\$ 8,178$ \\
\hline \multicolumn{6}{|l|}{ Hyperlipidemia } \\
\hline Total costs (Medical + Pharmacy) & $\$ 479$ & $\$ 469$ & $\$ 499$ & $\$ 325$ & $\$ 585$ \\
\hline Pharmacy & $\$ 428$ & $\$ 416$ & $\$ 452$ & $\$ 284$ & $\$ 531$ \\
\hline Medical & $\$ 51$ & $\$ 52$ & $\$ 46$ & $\$ 41$ & $\$ 53$ \\
\hline \multicolumn{6}{|l|}{ Hypertension } \\
\hline Total costs (Medical + Pharmacy) & $\$ 587$ & $\$ 480$ & $\$ 726$ & $\$ 948$ & $\$ 782$ \\
\hline Pharmacy & $\$ 307$ & $\$ 283$ & $\$ 342$ & $\$ 284$ & $\$ 347$ \\
\hline Medical & $\$ 280$ & $\$ 196$ & $\$ 384$ & $\$ 664$ & $\$ 435$ \\
\hline
\end{tabular}

2 to 3 times more than white and Hispanic HF patients (Table 3). A similar trend was apparent for asthma patients, with black and other race patients costing almost twice as much as white and Hispanic patients (Table 3).

All-cause ER visits and hospitalizations were high for all conditions. The percentage of patients with an all-cause ER visit ranged from $43 \%$ to $69 \%$, and hospitalizations ranged from $11 \%$ to $56 \%$ (Table 4 ). Fifteen percent of asthma patients had at least 1 disease-related ER visit; a larger percentage of blacks had at least 1 visit compared to whites, Hispanics, and other race. A total of $12 \%$ of HF patients had at least 1 disease-related hospitalization; here again, a larger percentage of blacks had at least 1 hospitalization compared to whites, Hispanics, and other race.

When evaluating the average costs for ER visits for patients with at least 1 such visit, black and other race patients were consistently more expensive per visit than white or Hispanic patients for all conditions with the exception of depression and HL, although the average number of visits was about the same across all patients (Table 5). Diseaserelated hospitalizations showed more of a mixed pattern for costs per visit. Black patients had the highest cost for a CADrelated stay than any other racial group.

\section{Discussion}

Findings from this 9-state analysis of Medicaid populations of more than 2.8 million point to considerable gaps that exist between national guidelines for quality of care and the chronic care services that are received, as documented by administrative claims data. One in 4 patients with asthma could potentially be better controlled as reflected in at least 4 prescription fills for SABAs in a year, and 12\% of COPD patients experiencing a Level II or III exacerbation. Only 31\% of patients with newly diagnosed depression had an antidepressant prescription fill within 90 days. Only 1 in 5 patients with diabetes had an eye exam in a year, and fewer than half $(45 \%)$ had the recommended acceptable number of A1c tests. The results reflecting poor quality of care among Medicaid patients corroborate results of a study of quality of care for diabetes in 27 community health centers. ${ }^{4}$ Patients with Medicaid or with no insurance were significantly less likely to meet quality of care measures than patients with private insurance or those who were dually eligible (both Medicare and Medicaid coverage). Similarly, in a study of the 383 health plans that reported quality of care data to the National Committee for Quality Assurance in 2002 and 2003, the performance of Medicaid plans (both those comprising Medicaid-only patients and commercial plans that also served Medicaid beneficiaries) was significantly poorer than commercial plans for all but 1 of 11 Healthcare Effectiveness Data and Information Set quality measures. ${ }^{5}$ The disparities in quality of care between Medicaid recipients and patients with other types of health care insurance underline the need for research to identify determinants of the differences in 
Table 4. Percent of Patients by All-Cause and Disease-Related ER Visits and Hospitalizations

\begin{tabular}{|c|c|c|c|c|c|}
\hline Event & All Patients & White & Black & Hispanic & Other \\
\hline \multicolumn{6}{|l|}{ All-cause ER visit } \\
\hline Asthma & $49 \%$ & $49 \%$ & $52 \%$ & $37 \%$ & $45 \%$ \\
\hline COPD & $63 \%$ & $63 \%$ & $68 \%$ & $56 \%$ & $57 \%$ \\
\hline Coronary artery disease & $61 \%$ & $63 \%$ & $70 \%$ & $56 \%$ & $45 \%$ \\
\hline Depression & $47 \%$ & $47 \%$ & $52 \%$ & $43 \%$ & $41 \%$ \\
\hline Diabetes & $55 \%$ & $57 \%$ & $60 \%$ & $52 \%$ & $42 \%$ \\
\hline $\mathrm{HF}$ & $69 \%$ & $68 \%$ & $73 \%$ & $64 \%$ & $62 \%$ \\
\hline Hyperlipidemia & $43 \%$ & $47 \%$ & $48 \%$ & $39 \%$ & $29 \%$ \\
\hline Hypertension & $50 \%$ & $52 \%$ & $53 \%$ & $42 \%$ & $37 \%$ \\
\hline \multicolumn{6}{|l|}{ All-cause hospitalization } \\
\hline Asthma & $11 \%$ & $11 \%$ & $11 \%$ & $7 \%$ & $10 \%$ \\
\hline COPD & $42 \%$ & $42 \%$ & $46 \%$ & $35 \%$ & $35 \%$ \\
\hline Coronary artery disease & $43 \%$ & $46 \%$ & $50 \%$ & $37 \%$ & $30 \%$ \\
\hline Depression & $20 \%$ & $19 \%$ & $25 \%$ & $14 \%$ & $16 \%$ \\
\hline Diabetes & $32 \%$ & $35 \%$ & $34 \%$ & $28 \%$ & $22 \%$ \\
\hline $\mathrm{HF}$ & $56 \%$ & $56 \%$ & $58 \%$ & $53 \%$ & $50 \%$ \\
\hline Hyperlipidemia & $21 \%$ & $25 \%$ & $23 \%$ & $16 \%$ & $10 \%$ \\
\hline Hypertension & $22 \%$ & $25 \%$ & $22 \%$ & $20 \%$ & $15 \%$ \\
\hline \multicolumn{6}{|l|}{ Disease-related ER visit } \\
\hline Asthma & $15 \%$ & $10 \%$ & $21 \%$ & $12 \%$ & $14 \%$ \\
\hline COPD & $13 \%$ & $14 \%$ & $13 \%$ & $11 \%$ & $12 \%$ \\
\hline Coronary artery disease & $8 \%$ & $10 \%$ & $8 \%$ & $5 \%$ & $5 \%$ \\
\hline Depression & $9 \%$ & $8 \%$ & $11 \%$ & $10 \%$ & $8 \%$ \\
\hline Diabetes & $8 \%$ & $7 \%$ & $10 \%$ & $7 \%$ & $5 \%$ \\
\hline $\mathrm{HF}$ & $13 \%$ & $9 \%$ & $18 \%$ & $8 \%$ & $10 \%$ \\
\hline Hyperlipidemia & $0.02 \%$ & $0.03 \%$ & $0.03 \%$ & None & None \\
\hline Hypertension & $3 \%$ & $2 \%$ & $4 \%$ & $3 \%$ & $2 \%$ \\
\hline \multicolumn{6}{|c|}{ Disease-related hospitalization } \\
\hline Asthma & $2 \%$ & $1 \%$ & $3 \%$ & $2 \%$ & $2 \%$ \\
\hline COPD & $7 \%$ & $7 \%$ & $7 \%$ & $4 \%$ & $7 \%$ \\
\hline Coronary artery disease & $9 \%$ & $10 \%$ & $8 \%$ & $5 \%$ & $7 \%$ \\
\hline Depression & $5 \%$ & $5 \%$ & $5 \%$ & $5 \%$ & $3 \%$ \\
\hline Diabetes & $4 \%$ & $4 \%$ & $5 \%$ & $3 \%$ & $2 \%$ \\
\hline $\mathrm{HF}$ & $12 \%$ & $9 \%$ & $17 \%$ & $9 \%$ & $10 \%$ \\
\hline Hyperlipidemia & $0.01 \%$ & $0.01 \%$ & $0.01 \%$ & None & None \\
\hline Hypertension & $0 \%$ & $0 \%$ & $1 \%$ & $0 \%$ & $0 \%$ \\
\hline
\end{tabular}

COPD, chronic obstructive pulmonary disease; ER, emergency room; HF, heart failure.

quality of care by health insurance status. For this study in particular, quality of care was low for common chronic diseases in this population. Establishing the benchmark of the status of care for chronic disease is important to help policy makers and providers design interventions to improve quality of care for patients who suffer from chronic disease.

The finding that substantial numbers of patients across chronic disease diagnoses were not using any pharmacotherapy considered acceptable according to treatment guidelines also reflects substandard quality of care in this Medicaid population. Only $35 \%$ to $83 \%$ of patients filled any acceptable medication for their condition. Undertreatment was most prevalent for depression, asthma, and HL; only 35\%, 49\%, and $52 \%$ of these patients, respectively, filled a prescription for any acceptable therapy. Even for those who did fill prescriptions, patients in this Medicaid population were generally poorly adherant to medication regimens. Persistence and compliance were especially poor for asthma and COPD, and the percentage of compliant patients did not exceed $75 \%$ even for $\mathrm{HF}$, the diagnosis typically associated with the highest adherence. For all conditions, blacks had lower persistence (10\% to $15 \%$ lower than whites) and compliance (12\% to $16 \%$ lower than whites) rates than any other race with the exception of HL, for which Hispanics had 1\% lower persistence. These data are consistent with results of studies showing that nonadherence is particularly widespread among patients with chronic conditions that require long-term drug therapy. ${ }^{6-8,27-31}$ Because the results of the current study are based on pharmacy claims, compliance is likely an overestimate of patients' true adherence to medication regimens. The number of days of medication supply and the patient's refilling behavior reflect the availability of medication to the patient but do not indicate whether a patient actually takes the medication at the time and in the manner prescribed.

Across diagnoses, $43 \%$ to $69 \%$ of these Medicaid-dependent patients had at least 1 all-cause ER visit in a year and $11 \%$ to $56 \%$ had at least 1 hospitalization. The high rate of ER visits and hospitalizations among Medicaid-dependent patients might be attributed in part to their relatively poor access to preventive and follow-up care. ${ }^{2,3}$ Considered in the context of previous findings, the utilization data from this study, which demonstrate poor access to care among Medicaid patients, highlight the need to improve care across the continuum of preventive, acute, and follow-up care. 
Table 5. Disease-Related ER Visits and Hospitalizations and Costs For Patients With $\geq 1$ ER Visit or Hospitalization

\begin{tabular}{|c|c|c|c|c|c|}
\hline & All Patients & White & Black & Hispanic & Other \\
\hline \multicolumn{6}{|c|}{$\begin{array}{l}\text { Disease-Related Emergency Room Utilization and Cost } \\
\text { Mean visits }\end{array}$} \\
\hline \multicolumn{6}{|c|}{ Mean \$cost/visit* } \\
\hline \multirow[t]{2}{*}{ Asthma } & 1.6 & 1.5 & 1.7 & 1.5 & 1.7 \\
\hline & $\$ 261$ & $\$ 223$ & $\$ 306$ & $\$ 226$ & $\$ 342$ \\
\hline \multirow[t]{2}{*}{ COPD } & 1.9 & 1.9 & 2.1 & 1.3 & 1.9 \\
\hline & $\$ 670$ & $\$ 585$ & $\$ 1,109$ & $\$ 545$ & $\$ 719$ \\
\hline \multirow[t]{2}{*}{ Coronary artery disease } & 1.5 & 1.6 & 1.5 & 1.5 & 1.5 \\
\hline & $\$ 856$ & $\$ 784$ & $\$ 1,113$ & $\$ 198$ & $\$ 936$ \\
\hline \multirow{2}{*}{ Depression } & 1.5 & 1.5 & 1.5 & 1.8 & 1.5 \\
\hline & $\$ 345$ & $\$ 320$ & $\$ 365$ & $\$ 492$ & $\$ 494$ \\
\hline \multirow[t]{2}{*}{ Diabetes } & 1.8 & 1.8 & 1.9 & 1.9 & 1.7 \\
\hline & $\$ 852$ & $\$ 630$ & $\$ 1,177$ & $\$ 348$ & $\$ 1,028$ \\
\hline \multirow[t]{2}{*}{$\mathrm{HF}$} & 2.2 & 1.9 & 2.3 & 1.8 & 2.2 \\
\hline & $\$ 1,247$ & $\$ 827$ & $\$ 1,568$ & $\$ 258$ & $\$ 1,670$ \\
\hline \multirow[t]{2}{*}{ Hyperlipidemia } & 1.2 & 1.2 & 1.2 & & \\
\hline & $\$ 271$ & $\$ 289$ & $\$ 130$ & none & none \\
\hline \multirow[t]{2}{*}{ Hypertension } & 1.4 & 1.4 & 1.4 & 2.8 & 1.4 \\
\hline & $\$ 338$ & $\$ 290$ & $\$ 368$ & $\$ 690$ & $\$ 297$ \\
\hline \multirow{2}{*}{\multicolumn{6}{|c|}{$\begin{array}{l}\text { Disease-Related Hospitalizations and Cost } \\
\text { Mean visits }\end{array}$}} \\
\hline & \multicolumn{5}{|c|}{ Mean visits } \\
\hline \multicolumn{6}{|l|}{ Mean \$cost/visit* } \\
\hline \multirow{2}{*}{ Asthma } & 1.3 & 1.2 & 1.3 & 1.2 & 1.3 \\
\hline & $\$ 8,592$ & $\$ 5,294$ & $\$ 10,978$ & $\$ 4,569$ & $\$ 13,118$ \\
\hline \multirow[t]{2}{*}{ COPD } & 1.7 & 1.6 & 1.8 & 1.2 & 1.5 \\
\hline & $\$ 13,634$ & $\$ 12,465$ & $\$ 17,413$ & $\$ 19,541$ & $\$ 20,027$ \\
\hline \multirow[t]{2}{*}{ Coronary artery disease } & 1.6 & 1.6 & 1.6 & 1.7 & 1.6 \\
\hline & $\$ 28,834$ & $\$ 25,241$ & $\$ 44,819$ & $\$ 24,197$ & $\$ 24,916$ \\
\hline \multirow[t]{2}{*}{ Depression } & 1.5 & 1.5 & 1.5 & 2.1 & 1.5 \\
\hline & $\$ 8,787$ & $\$ 8,391$ & $\$ 10,415$ & $\$ 12,721$ & $\$ 3,999$ \\
\hline \multirow[t]{2}{*}{ Diabetes } & 1.7 & 1.6 & 1.8 & 2.0 & 1.7 \\
\hline & $\$ 18,865$ & $\$ 14,195$ & $\$ 24,964$ & $\$ 12,479$ & $\$ 24,831$ \\
\hline \multirow[t]{2}{*}{$\mathrm{HF}$} & 2.0 & 1.8 & 2.1 & 1.8 & 1.9 \\
\hline & $\$ 28,364$ & $\$ 22,855$ & $\$ 31,285$ & $\$ 14,089$ & $\$ 44,525$ \\
\hline \multirow[t]{2}{*}{ Hyperlipidemia } & 1.2 & 1.2 & 1.4 & & \\
\hline & $\$ 4,283$ & $\$ 3,898$ & $\$ 5,820$ & none & none \\
\hline \multirow[t]{2}{*}{ Hypertension } & 1.4 & 1.2 & 1.3 & 2.7 & 1.3 \\
\hline & $\$ 11,654$ & $\$ 7,292$ & $\$ 14,310$ & $\$ 17,165$ & $\$ 12,960$ \\
\hline
\end{tabular}

*All patients are included in the mean visits but only patients enrolled in a fee-for-service plan are included in the cost calculations. COPD, chronic obstructive pulmonary disease; ER, emergency room; HF, heart failure.

With the rising unemployment rate, Medicaid is being flooded with new enrollees. It is important to focus on disease prevention as well as the appropriate treatment for patients living with chronic disease to provide better quality of care and to help control costs. Identifying opportunities with the greatest impact (eg, adherence programs targeted toward black patients with chronic disease) could help to identify smaller, more manageable subsets of patients to receive interventions to improve care, which is extremely important given the limited financial resources to the system. With the passage of health care reform and the resultant lessening of financial requirements for enrollment in Medicaid, additional resources and patients will have an impact on the health care system. Ensuring that quality of care is enhanced for the entire Medicaid population, including the new enrollees, will be of major social and medical interest.

Several limitations should be considered when interpreting the results of this study. First, the health care cost and utilization data were not adjusted for comorbidities, which were likely highly prevalent in this patient population. Data were not adjusted for comorbidities in order to provide a comprehensive and realistic gauge of the economic burden of chronic diseases in the patient population. Due to limitations of the data, dual-eligible patients and those age 65 years and older were excluded and only costs for those enrolled in a FFS plan were assessed. Therefore, these results are not generalizable to all Medicaid patients. Other limitations include the study's reliance on diagnosis coding, which can be inaccurate and incomplete, and its retrospective, observational design, which allows for the possibility of confounding and various biases. The data presented are descriptive in nature only and were not designed to determine racial disparities using multivariate methodologies; the results only show the need for future research using statistical modeling to control for factors that may confound the results. Strengths of the study include its large, representative 
sample and its conduct in the "real-world" setting. To the authors' knowledge, this study is the first systematic investigation of quality of care and medication adherence for multiple chronic diseases in a large Medicaid population.

It was not feasible to include all data for each condition in this article. Analyses were also conducted that were stratified by patients enrolled in FFS and managed Medicaid plans. There were differences in demographics between the two cohorts but there were only minor differences in the outcomes evaluated for this study. Additional results by condition are available upon request. It is the authors' intent to post all results online.

\section{Conclusion}

The purpose of this study was to benchmark a largely underserved population using common claims data so that we can begin to address the issues using interventions such as coordinated care (Medical Home ${ }^{32}$ ), education, and preventive care, and by encouraging less use of ER/hospital and increased use of outpatient services. The results from this study show that low-quality care and poor medication adherence were prevalent and that health care resource costs and utilization were considerable for 8 common chronic diseases in a Medicaid population of more than 2.8 million patients. There were also distinct racial differences in medication adherence for all conditions and some differences in health care costs and utilization that need to be studied further. Coordinated care could reduce ER visits and hospitalizations and increase preventive care. The medical home model may be one way to address these issues in this population. Implications of these results include the need for improved quality of care for Medicaid patients and more targeted interventions by race for medication adherence. Additional research is necessary to address serious disparities in the quality of care received in general, and specific attention must focus on examining the correlates and predictors of differing levels of care within subpopulations, such as racial differences in the quality of care received.

\section{Acknowledgments}

The authors thank Jane Saiers, PhD, for assistance with writing this manuscript and Tim Niecko, MS, for his independent validation of the programming code used to conduct the analysis. GlaxoSmithKline funded Dr. Saiers' and Mr. Niecko's work for this study.

\section{Author Disclosure Statement}

Ms. Priest, Dr. Cantrell, Dr. Cook and Dr. Burch are all employees of GlaxoSmithKline and own stock in the company based on employment benefits. Dr. Fincham disclosed no conflicts of interest.

\section{References}

1. McGlynn EA, Asch SM, Adams J, et al. The quality of health care delivered to adults in the United States. N Engl J Med 2003;348;2635-2645.

2. Giacovelli JK, Egorova N, Nowygrod R, et al. Insurance status predicts access to care and outcomes of vascular disease. J Vasc Surg 2008;48:905-911.

3. Blanchard J, Ogle K, Thomas O, Lung D, Asplin B, Lurie N. Access to appointments based on insurance status in Wa- shington, D.C. J Health Care Poor Underserved 2008;19:687696.

4. Zhang JX, Huang ES, Drum ML, et al. Insurance status and quality of diabetes care in community health centers. Am J Public Health 2008;99:742-747.

5. Landon BE, Schneider EC, Normand SL, Scholle SH, Pawlson LG, Epstein AM. Quality of care in Medicaid managed care and commercial health plans. JAMA 2007;298: 1674-1681.

6. Melfi CA, Croghan TW, Hanna MP, Robinson RL. Racial variation in antidepressant treatment in a Medicaid population. J Clin Psychiatry 2000;61:16-21.

7. Shenolikar R, Balkrishnan R, Camacho FT, Whitmire JT, Anderson RT. Race and medication adherence in Medicaid enrollees with type-2 diabetes. J Natl Med Assoc 2006;98: 1071-1077.

8. Bagchi AD, Esposito D, Kim M, Verdier J, Bencio D. Utilization of, and adherence to, drug therapy among Medicaid beneficiaries with congestive heart failure. Clin Ther 2007; 29:1771-1783.

9. Donnelly LA, Morris AD, Evans JM. Adherence to insulin and its association with glycaemic control in patients with type 2 diabetes. QJM 2007;100:345-350.

10. Kennedy S, McIntyre R, Fallu A, Lam R. Pharmacotherapy to sustain the fully remitted state. J Psychiatry Neurosci 2002;27:269-280.

11. White TJ, Vanderplas A, Ory C, Dezii CM, Chang E. Economic impact of patient adherence with antidepressant therapy within a managed care organization. Dis Manag Health Outcomes 2003;11:817-822.

12. Lee WC, Balu S, Cobden D, Joshi AV, Pashos CL. Prevalence and economic consequences of medication adherence in diabetes: A systematic literature review. Manag Care Interface 2006;19:31-41.

13. Denhaerynck K, Manhaeve D, Dobbels F, Garzoni D, Nolte C, De Geest S. Prevalence and consequences of nonadherence to hemodialysis regimens. Am J Crit Care 2007;16:222-225.

14. Leucht S, Heres S. Epidemiology, clinical consequences, and psychosocial treatment of nonadherence in schizophrenia. J Clin Psychiatry 2006;67:3-8.

15. Sokol MC, McGuigan KA, Verbrugge RR, Epstein RS. Impact of medication adherence on hospitalization risk and healthcare cost. Med Care 2005;43:521-530.

16. Thomson Reuters. Marketscan research databases. Available at: http://thomsonreuters.com/products_services/healthcare/ healthcare_products/pharmaceuticals/epidemiology_res/ mktscan_res_db. Accessed May 20, 2010.

17. National Heart, Lung, and Blood Institute. Expert Panel Report 3: Guidelines for the diagnosis and management of asthma. Available at: http://www.nhlbi.nih.gov/guidelines/ asthma/asthgdln.pdf. Accessed June 8, 2008.

18. Donahue JG, Weiss ST, Livingston JM, Goetsch MA, Greineder DK, Platt R. Inhaled steroids and the risk of hospitalization for asthma. JAMA 1997;277:887-891.

19. American Thoracic Society/European Respiratory Society Task Force. Standards for the diagnosis and management of patients with COPD [Internet]. Version 1.2. New York: American Thoracic Society [Updated 2005 September 8]. Available at: http://www.thoracic.org/go/copd.

20. Kaiser Permanente Care Management Institute. Depression clinical practice guidelines. Oakland (CA): Kaiser Permanente Care Management Institute; 2006:196.

21. American Diabetes Association. Standards of medical care in diabetes. Diabetes Care 2004;27:S15-S35. 
22. Smith SC, Allen J, Blair S, et al. AHA/ACC Guidelines for secondary prevention for patients with coronary and other atherosclerotic vascular disease: 2006 update: endorsed by the National Heart, Lung, and Blood Institute. Circulation 2006;113:2363-2372.

23. Rodbard WH, Blonde L, Braithwaite SS, et al. American Association of Clinical Endocrinologists medical guidelines for clinical practice for the management of diabetes mellitus. Endoc Pract 2007;13:1-68.

24. Hunt SA, Abraham WT, Chin MH, et al. ACC/AHA 2005 guideline update for the diagnosis and management of chronic heart failure in the adult. Summary article. J Am Coll Cardiol 2005;46:1116-1143.

25. Eert Panel on Detection, Evaluation, and Treatment of High Blood Cholesterol in Adults. Executive Summary of the Third Report of the National Cholesterol Education Program (NCEP) Expert Panel on Detection, Evaluation, and Treatment of High Blood Cholesterol in Adults (Adult Treatment Panel III). JAMA 2001;285:2486-2497.

26. Chobanian AV, Bakris GL, Black HR, et al. Seventh report of the Joint National Committee on Prevention, Detection, Evaluation, and Treatment of High Blood Pressure. Hypertension 2003;42:1206-1252.

27. Sabaté E. Adherence to long-term therapies: evidence for action. Available at: http://www.who.int/chp/knowledge/ publications/adherence_report/en/. Accessed June 25, 2007.
28. Masand PS. Tolerability and adherences issues in antidepressant therapy. Clin Therapeut 2003;25:2289-2304.

29. Lin EH, Von Korff M, Katon W, et al. The role of the primary care physician in patients' adherence to antidepressant therapy. Med Care 1995;33:67-74.

30. Maddox JC, Levi M, Thompson C. The compliance with antidepressants in general practice. J Psychopharmacol 1994;8:48-53.

31. Rand C, Bilderback A, Schiller K, et al. Adherence with montelukast or fluticasone in a long-term clinical trial: Results from the mild asthma montelukast versus inhaled corticosteroid trial. J Allergy Clin Immunol 2007;119:916923.

32. Gill JM, Landon BE, Antonelli RC, Rich EC. Generating the knowledge needed to make the patient-centered medical home a reality: A collaborative project of the primary care specialties. Ann Fam Med 2010;8:88-89.

Address correspondence to: Julie L. Priest

Applied Outcomes and Analysis GlaxoSmithKline 5 Moore Drive

Research Triangle Park, NC 27709

E-mail: Julie.L.Priest@gsk.com 